\title{
Modified selective aortic root reconstruction with valve repair for treatment of Stanford A aortic dissection
}

\author{
Mohammed Abd Al Jawad
}

\begin{abstract}
Background: Acute aortic dissection is a serious emergency with a significant impact on mortality and morbidity. Many patients present with hemodynamic instability that may prevent them from being transported to more experienced centers. We aim to present our experience with a modified limited root approach in terms of the operative details and early results.
\end{abstract}

Results: This retrospective study included 27 patients who presented with Stanford A aortic dissection and underwent modified selective root replacement. All patients were followed up using transthoracic echocardiography at 6 months postoperatively and at yearly intervals thereafter. Computed tomography $(\mathrm{CT})$ angiography was performed 12 months after the initial surgery.

A total of $92.6 \%$ of patients required concomitant aortic valve repair. There was no operative mortality related to the operation itself; however, four patients died during the follow-up period. One patient developed new severe aortic regurgitation in the 6th month of follow-up. One patient developed a pseudoaneurysm related to the suture line that was diagnosed by CT angiography in the 16th month of follow-up.

Conclusions: The early results of modified selective root reconstruction with aortic valve repair are promising. This procedure is a quick, reliable, easily reproducible, and technically undemanding valve-sparing treatment for acute aortic root dissection.

Keywords: Aortic dissection, Aortic root, Stanford type A, Root reconstruction, Valve sparing

\section{Background}

Acute Stanford type A aortic dissection is one of the most challenging scenarios encountered in the emergency room (ER), a true emergency that is associated with very high risks of morbidity and mortality [1]. The surgical management of aortic dissection has evolved along a circuitous path and is constantly being challenged by many authors. The main concerns are the extent and length of the operation in this fragile group of patients [2].

The trend toward aggressive root replacement with the addition of valve-sparing procedures demands a new level of

Correspondence: mohammed_abdaljawad@med.asu.edu.eg

Department of Cardiothoracic Surgery, Faculty of Medicine, Ain Shams

University, Abbaseya Square, Cairo, Egypt expertise and has a slow learning curve for many surgeons, necessitating the concept of an "aortic center" [2,3].

Unfortunately, the concept of an "aortic center" may not be feasible for developing countries, and even if such a center exists, unnecessary transport delays hinder properly timed definitive management. If a simpler intervention was developed many rural areas with cardiac surgery capabilities and acceptable levels of training could save many high-risk or hemodynamically unstable patients without the risks involved in transporting them.

In this study, we aim to present our experience by evaluating the clinical and echocardiographic results of modified limited root reconstruction in the context of aortic dissection.

\section{Springer Open}

(c) The Author(s). 2020 Open Access This article is licensed under a Creative Commons Attribution 4.0 International License, which permits use, sharing, adaptation, distribution and reproduction in any medium or format, as long as you give appropriate credit to the original author(s) and the source, provide a link to the Creative Commons licence, and indicate if changes were made. The images or other third party material in this article are included in the article's Creative Commons licence, unless indicated otherwise in a credit line to the material. If material is not included in the article's Creative Commons licence and your intended use is not permitted by statutory regulation or exceeds the permitted use, you will need to obtain permission directly from the copyright holder. To view a copy of this licence, visit http://creativecommons.org/licenses/by/4.0/. 


\section{Methods}

This retrospective observational study included 27 patients who had Stanford type A aortic dissection involving the root and underwent modified selective root reconstruction with or without aortic valve repair. The study took place in the Ain Shams University Hospitals, spanning from July 2014 until October 2019. The study protocol was revised and approved by the Ethical Committee at our institute, by which patient consent was waived due to the retrospective nature of the study.

All patients were followed up using transthoracic echocardiography at 6 months postoperatively and on a yearly basis afterward or whenever clinical symptoms are indicated. Computed tomography (CT) angiography was performed 12 months after the initial operation to evaluate false lumen thrombosis and remodeling in the native residual aortic segments. Positive aortic remodeling was defined by obliteration of the proximal entry point with subsequent reduction of the false lumen along with a corresponding increase in the size of the true lumen and, ultimately, obliteration of the false lumen. Negative remodeling was defined as a failure of reduction of the false lumen, pseudoaneurysm formation, or persistence of the side branch arising from the false lumen [4].

The primary endpoint of the study was operative mortality. The secondary endpoints were all-cause mortality during follow-up; the occurrence of new aortic regurgitation (AR) above grade 2+ on transthoracic echocardiogram or of residual dissection or pseudoaneurysm on CT angiography by the 12-month follow-up; reoperation for AR; residual dissection or pseudoaneurysm; and significant postoperative complications.

\section{Surgical technique}

Cardiopulmonary bypass $(\mathrm{CPB})$ was performed through femoral artery cannulation in 24 patients and innominate artery cannulation in 3 patients. Venous cannulation was determined according to associated procedures, e.g., mitral replacement. The target temperature range was 20.1-28 ${ }^{\circ} \mathrm{C}$ (moderate hypothermia) as measured by a nasopharyngeal probe.

Once the heart entered cardioplegic arrest, the aorta was incised, and the root was carefully examined. If dissection involved the root at the noncoronary sinus and/
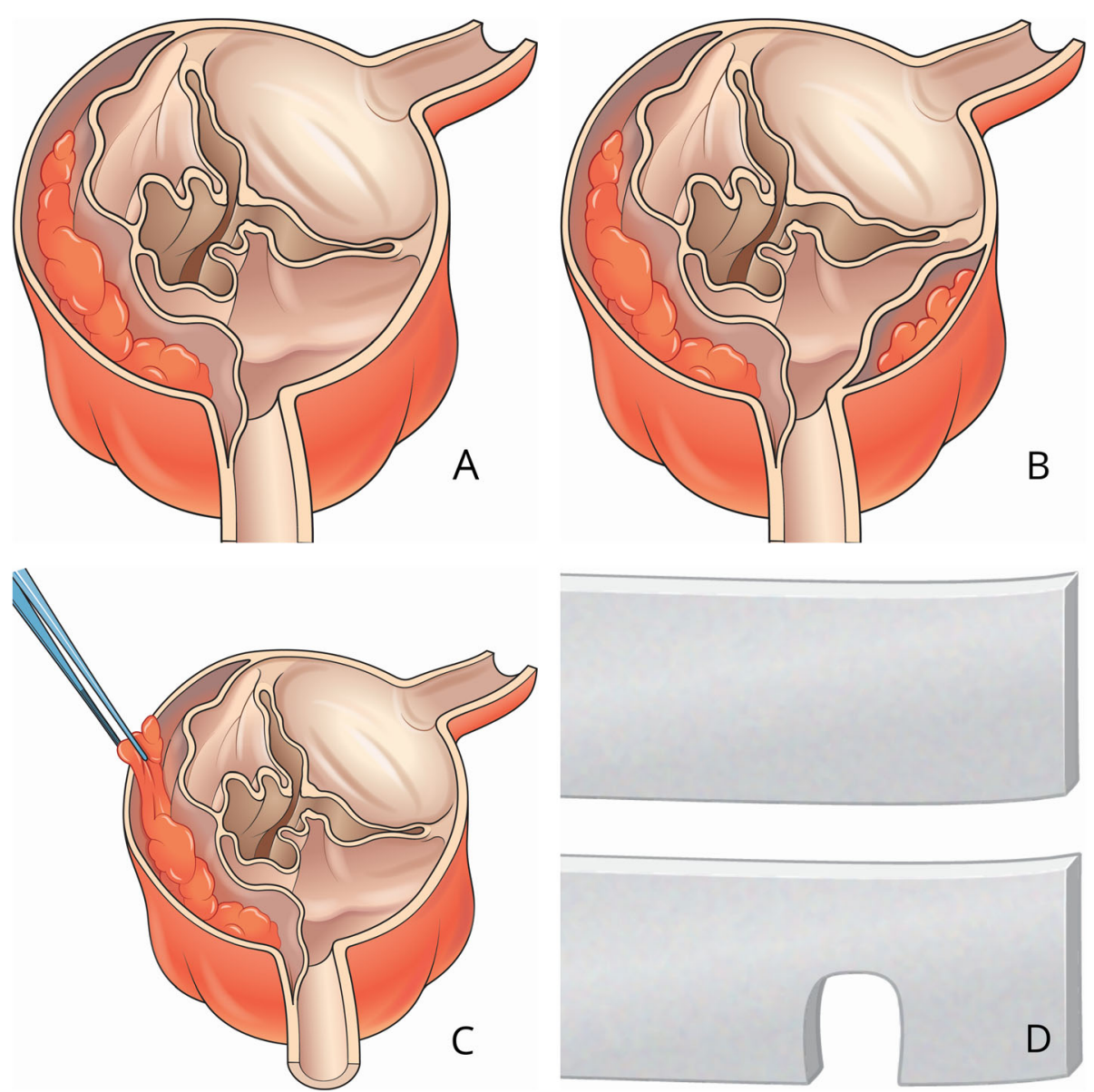

Fig. 1 Operative sighting of the aortic root and preparation for the procedure 
or the right coronary sinus, i.e., sparing the left coronary sinus and ostium, the repair was carried out even if there was an extension of the flap to the right coronary ostia (Fig. 1a, b). The valve leaflets were thoroughly examined to determine whether they were bicuspid or tricuspid and to assess their leaflet pliability, calcification, and raphe fibrosis in bicuspids. Additionally, the geometric height of the leaflets $(\mathrm{gH})$ was roughly estimated. If this value was less than $17 \mathrm{~mm}$ in the tricuspid valve or less than $20 \mathrm{~mm}$ in the bicuspid valve, repair was not carried out.

The root was debrided from any thrombi or blood clots and then irrigated with normal saline solution to remove any nonvisible particles; this debridement must reach as far down into the root as possible (Fig. 1c).

A polytetrafluoroethylene (PTFE) patch was cut and fashioned as a strip (for the noncoronary sinus) and/or a strip with an arched opening (to fit in the shape of a saddle above the right coronary ostia) (Fig. 1d).

The patch(es) were then squeezed in the dissected sinuses, reaching as down as possible in the root. The patches were held in place using interrupted $5 / 0$ polypropylene sutures from the inside (Fig. 2a).

Just before the sutures were tightened, a very thin film of BioGlue was applied on both sides of the patch. The film was both thin and homogenous to prevent any bumps on the endothelial side (Fig. 2b).

A sharp scissor was used to trim the upper edges of the patch to achieve an orderly, circular, uniform new aortic wall (Fig. 2c). This step was followed by valve resuspension, subcommissural annuloplasty, and/or leaflet plication as an adjunct repair to nullify residual AR (Fig. 2d).

Aortic valve repairs included resuspension and subcommissural annuloplasty as a basic step in all patients. Any leaflet calcification or raphe fibrosis was gently shaved away with a sharp scalpel to increase the pliability of the leaflet. A 6/0 Prolene suture was passed through the central free margin of each leaflet, stretching every pair of leaflets together to identify any excess tissue that might cause leaflet to prolapse. The prolapsed leaflet was then plicated with a 6/0 Prolene suture to
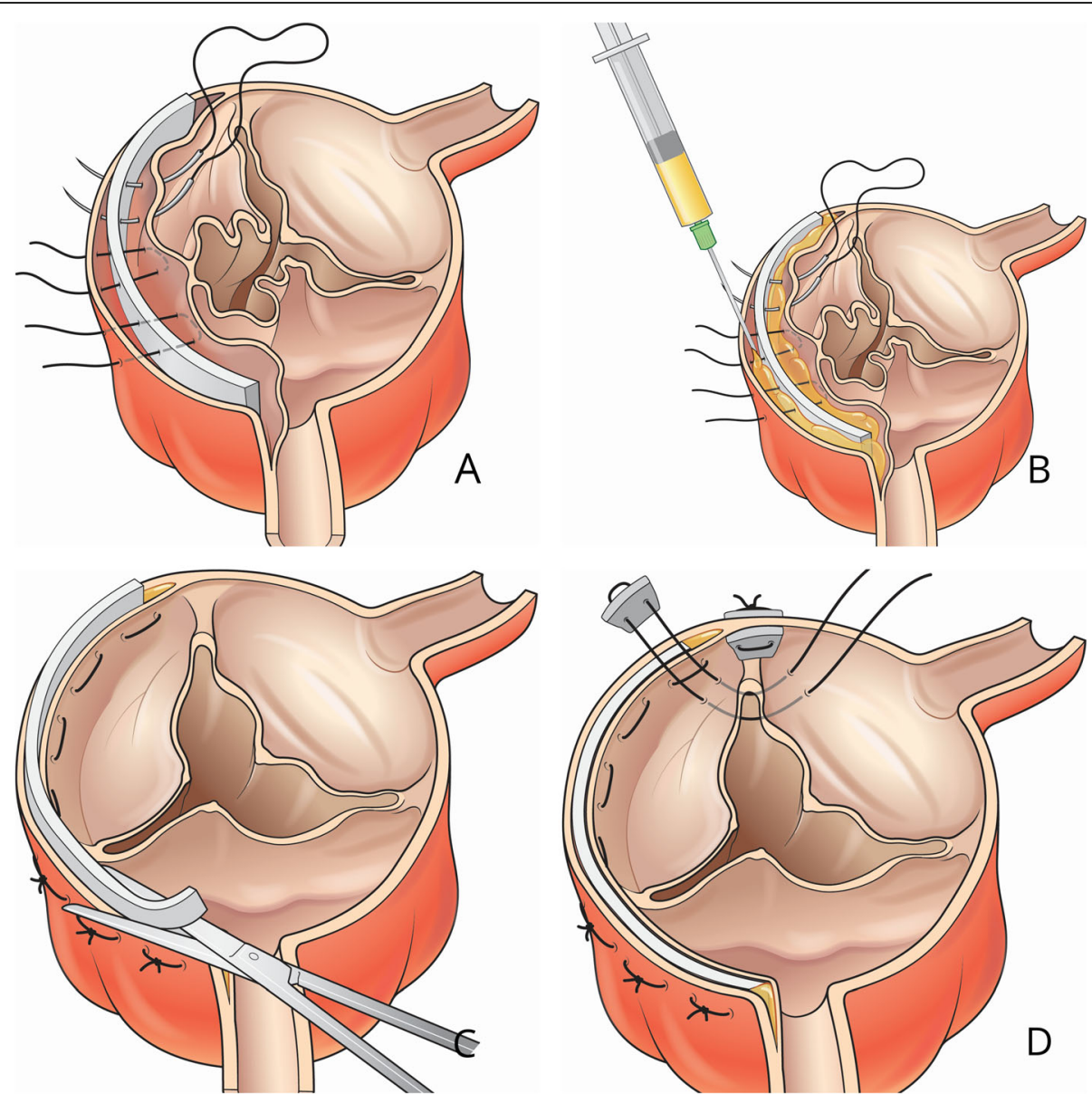

Fig. 2 Basic steps of repair 
achieve equal length. The central plication was used to increase the effective height of the leaflet $(\mathrm{eH})$.

The key element of leaflet repair is to achieve good coaptation between all leaflets at two levels: above the annulus and at the annulus. Due to the lack of a special caliper in our institute, more difficult repairs were discouraged.

These steps were followed by an interposition graft to replace the ascending aorta. The dissected distal end of the aorta was obliterated by another patch of PTFE with an additional external PTFE support from the outside. Total circulatory arrest was needed in 3 patients to achieve good distal anastomosis, and all three patients were given unilateral antegrade cerebral perfusion via innominate artery cannulation.

\section{Statistical analysis}

The results were expressed as numbers (mean values and standard deviation, median, and range) and percentages as appropriate. Kaplan-Meier survival analysis was performed using MedCalc ${ }^{\circ}$ v.14.8.1.

\section{Results}

The mean age of the patients included in the study was $48.15 \pm 10.92$ years, denoting a relatively young cohort; $85.1 \%$ of patients were male with systemic hypertension as a comorbidity; $77.8 \%$ of patients presented with acute Stanford type A dissection (Table 1).

Table 1 Patients' demographics and characteristics

\begin{tabular}{lll}
\hline & \multicolumn{2}{l}{$\begin{array}{l}\text { Selective root + repair } \\
n=27\end{array}$} \\
\hline Age (years) & $48.15 \pm 10.92$ & \\
Sex (male) & 23 & $85.1 \%$ \\
NYHA I-II & 11 & $40.7 \%$ \\
NYHA III-IV & 16 & $59.3 \%$ \\
Comorbidities & & \\
- HTN & 19 & $70.4 \%$ \\
- DM & 2 & $7.4 \%$ \\
- CAD & 1 & $3.7 \%$ \\
- COPD & 4 & $14.8 \%$ \\
- CT disease & 0 & $0 \%$ \\
- Cerebral malperfusion & 0 & $0 \%$ \\
- Renal impairment (Cr > 1.7 mg/dl) & 1 & $3.7 \%$ \\
- Malperfusion of another organ & 2 & $7.4 \%$ \\
Aortic dissection & & \\
- Acute & & \\
- Chronic & 21 & $77.8 \%$ \\
\hline $\begin{array}{l}\text { Values are shown as numbers, percentages, mean } \pm \text { SD. NYHA New York Heart } \\
\text { Association class, HTN hypertension, DM diabetes mellitus, CAD coronary artery } \\
\text { disease, COPD chronic obstructive pulmonary disease, CT connective tissue, Cr } \\
\text { creatinine, mg/dl milligram(s) per deciliter }\end{array}$ &
\end{tabular}

A total of $85.2 \%$ of patients had more than grade $2 \mathrm{AR}$ as an echocardiographic finding, and $74 \%$ of patients had a tricuspid aortic valve configuration (Table 2).

A total of $92.6 \%$ of patients required additional aortic valve repair rather than valve resuspension and/or subcommissural annuloplasty. Additional procedures included 2 patients who required an additional saphenous vein graft (SVG) to the right system, one patient who required SVG to the left anterior descending artery (LAD), and one patient who required a concomitant mitral valve replacement. Operative details are shown in Table 3.

There was no operative-related mortality; however, during the follow-up period, four patients were deceased. The first patient sustained a significant neurological disability causing severe bulbar affection and died during the first month of follow-up. The second death was due to a newly developed severe AR, causing heart failure diagnosed in the 6th month of follow-up; the patient was operated on for aortic valve replacement (AVR) and died 1 month after the second operation. The third patient developed a pseudoaneurysm related to the suture line that was diagnosed by CT angiography in the 16th month of follow-up, he was operated on, and the sac was found to be infected. He later died of septicemia. The fourth death was mostly due to sudden fatal arrhythmia in the 23rd month (Tables 4 and 5).

Kaplan-Meier survival analysis showed a 5-year survival rate of $83 \%$ for the study cohort (Fig. 3).

During a follow-up period of $30.96 \pm 17.82$ (median 29 months), $96.3 \%$ of patients had $\leq 2$ AR by echocardiography. Of the 27 patients included in the study, 22 patients reached the one-year milestone at which followup CT angiography showed thrombosis of the false lumen and positive remodeling with no residual dissection in 21 patients (Table 5).

\section{Discussion}

The Bentall procedure was one of the earliest approaches of acute aortic dissection involving the root by replacing the ascending aorta and valve with a prefabricated valved conduit $[1,2]$.

Table 2 Preoperative echocardiographic findings

\begin{tabular}{lll}
\hline \multicolumn{3}{c}{$\begin{array}{l}\text { Selective root + repair } \\
n=27\end{array}$} \\
\hline EF & $52.53 \pm 9.17$ \\
Aortic insufficiency & & \\
$\cdot \leq 2$ & 4 & $14.8 \%$ \\
$\cdot>2$ & 23 & $85.2 \%$ \\
Aortic valve morphology & & \\
$\cdot$ Bicuspid & 7 & $26 \%$ \\
$\cdot$ Tricuspid & 20 & $74 \%$ \\
\hline
\end{tabular}

Values are shown as numbers, percentages, mean \pm SD. EF ejection fraction 
Table 3 Operative details

\begin{tabular}{|c|c|c|}
\hline & \multicolumn{2}{|c|}{$\begin{array}{l}\text { Selective } \\
\text { root }+ \text { repair } \\
n=27\end{array}$} \\
\hline ACX time (min) & \multicolumn{2}{|c|}{$124.4 \pm 22.2$} \\
\hline Bypass time (min) & \multicolumn{2}{|c|}{$194 \pm 53$} \\
\hline \multicolumn{3}{|l|}{ Arterial cannulation } \\
\hline - Innominate artery & 3 & $11.1 \%$ \\
\hline - Femoral artery & 24 & $88.9 \%$ \\
\hline Lowest temperature, ${ }^{\circ} \mathrm{C}$ & \multicolumn{2}{|c|}{$23.74 \pm 3.87$} \\
\hline Circulatory arrest & 3 & $11.1 \%$ \\
\hline Circulatory arrest time (min) & \multicolumn{2}{|c|}{$26 \pm 12.16$} \\
\hline \multicolumn{3}{|l|}{ Cerebral perfusion during circulatory arrest } \\
\hline - Antegrade & 3 & $100 \%$ \\
\hline - Retrograde & 0 & $0 \%$ \\
\hline Concomitant procedures & 4 & \\
\hline - CABG (SVG to RCA) & 2 & \\
\hline - CABG (SVG to LAD) & 1 & \\
\hline$\cdot \mathrm{MVR}$ & 1 & \\
\hline $\begin{array}{l}\text { Aortic valve repair (leaflet other than SCA and } \\
\text { resuspension) }\end{array}$ & 25 & $92.6 \%$ \\
\hline
\end{tabular}

Values are shown as numbers, percentages, mean $\pm \mathrm{SD}$. $A C X$ aortic crossclamp, min minutes, CABG coronary artery bypass grafting, SVG saphenous vein graft, $R C A$ right coronary artery, $L A D$ left anterior descending coronary artery, MVR mitral valve replacement, SCA subcommissural annuloplasty

For a long time, it has been considered the gold standard for root replacement [5]. Since its first adoption, it underwent several modifications that decreased rates of reoperation following the primary procedure [6]. Most of the Bentall procedures performed today utilize mechanical valves owing to their longer duration, yet this carries its own risk of thromboembolic complications and life-long commitment to anticoagulation [7].

However, this was challenged later by the trend of sparing the native valve in younger patients without apparent leaflet disease [8]. The adoption of valve-sparing techniques revolutionized the concept of managing such pathology [9].

Table 4 Postoperative in-hospital outcomes

\begin{tabular}{|c|c|c|}
\hline \multirow[b]{2}{*}{ Operative mortality } & \multicolumn{2}{|c|}{$\begin{array}{l}\text { Selective root + repair } \\
n=27\end{array}$} \\
\hline & 0 & $0 \%$ \\
\hline Other mortality (ICU, ward) & 0 & $0 \%$ \\
\hline Permanent neurological impairment & 1 & $3.7 \%$ \\
\hline Transient neurological impairment & 3 & $11.1 \%$ \\
\hline New onset of dialysis & 0 & $0 \%$ \\
\hline GIT complications & 0 & $0 \%$ \\
\hline Re-exploration & 2 & $7.4 \%$ \\
\hline
\end{tabular}

Values are shown as numbers, percentages, mean \pm SD. ICU intensive care unit, GIT gastrointestinal tract
Whether first introduced by Yacoub as "remodeling" [10] or later by David as "reimplantation" [11], both share the same principle of replacing the ascending aorta and root with a prosthetic conduit while preserving the native aortic valve, differing only in the treatment of the aortic sinuses $[11,12]$

This revolutionary concept came with the high technical cost of replacing the whole ascending aorta, valve repair, and reimplanting the coronary buttons. Additionally, extensive experience is required both to perform the operation and to select the suitable patient who will benefit from such complicated procedures with the least unfavorable results, with many experienced centers not recommending the procedure for high-risk and elderly patients [2].

Since then, surgeons have realized that restoration of normal root geometry can indeed restore aortic valve competence [9]. Additionally, David and colleagues showed that a reduction of the sinotubular junction (STJ) diameter can achieve even better coaptation of the aortic valve with normal leaflets, leading to a newer concept of "isolated aortic valve repair" [13].

One of the most basic and efficient valve repair techniques is "central plication" of the free margin of the leaflet; shortening the free margin causes the effective height $(\mathrm{eH})$ to increase, thus ensuring better coaptation. A surgeon must ensure that residual leaflet tissue is available before proceeding with the repair; as a rule of thumb, the geometric height $(\mathrm{gH})$ should be at least 17 $\mathrm{mm}$ in the tricuspid valve and at least $20 \mathrm{~mm}$ in the bicuspid valve for all leaflets together [14].

It is difficult to calculate the long-term outcome of many valve-sparing procedures since most published data include the repair of both tricuspid and bicuspid valves. However, for isolated valve repair, the 5-year freedom from intervention was $95 \%$ if the AR was due to prolapse and no leaflet restriction [15].

The mere adhesion of a dissected aortic wall by means of biocompatible glue is a simple and efficient way to

Table 5 Postoperative follow-up data

\begin{tabular}{|c|c|c|}
\hline \multirow[b]{2}{*}{ Follow-up death } & \multicolumn{2}{|c|}{$\begin{array}{l}\text { Selective root +repair } \\
n=27\end{array}$} \\
\hline & 4 & $14.8 \%$ \\
\hline Follow-up period & $30.96 \pm 17.82$ & Median 29 \\
\hline \multicolumn{3}{|l|}{ Aortic insufficiency } \\
\hline$\cdot \leq 2$ & 26 & $96.3 \%$ \\
\hline$\cdot>2$ & 1 & $3.7 \%$ \\
\hline Reoperation for aortic valve & 1 & $3.7 \%$ \\
\hline Reoperation for residual dissection & 0 & $0 \%$ \\
\hline Reoperation for pseudoaneurysm & 1 & $3.7 \%$ \\
\hline 1-year remodeling $(n=22)$ & 21 (positive) & $95.4 \%$ \\
\hline
\end{tabular}

Values are shown as numbers, percentages, mean \pm SD 


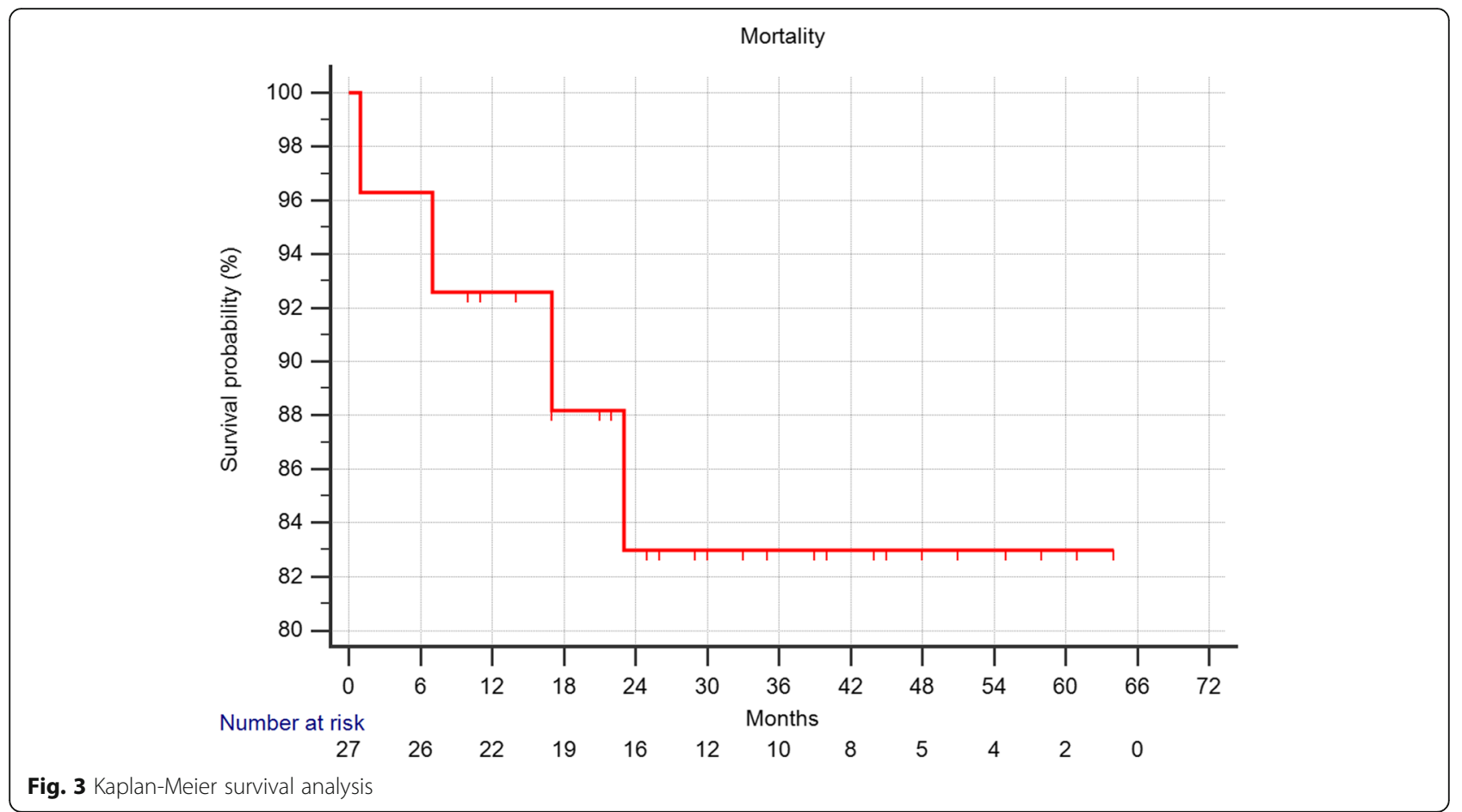

restore the aortic root configuration. This technique is beneficial in reconstructing dissected sinuses in fragile, severely ill patients who might benefit from short, simple interventions [1]. The critical drawback of this technique is that it is noncurative, potentially resulting in the need for reoperation [2].

The principle of our technique is based on combining three approaches. The first approach is the Stanford and Cleveland Clinic approach, which has always been conservative in dealing with a dissected root using a supracoronary graft, valve resuspension, and/or sinus repair [2]. To achieve a reduction in the sinotubular junction (STJ), we tend to use a graft size of 30 for males and 28 for females. The second approach is that of the Leipzig group, who found that "limited root remodeling" to replace one or two sinuses, i.e., the Uni/Bi Yacoub procedure, has results comparable to those of David's reimplantation procedure $[1,16]$; hence, we used sandwiched PTFE patches in selected sinuses. The third approach is the concept of utilizing BioGlue to reconstruct aortic wall sinuses.

\section{Limitations of the study}

Our study has some limitations that should be acknowledged. In particular, the design is retrospective, and the number of patients is small. Furthermore, this study is limited to short-term data, and a longer follow-up is needed. Due to the extremely low rate of adverse events, it is not possible to determine small differences in favor of this technique or its alternatives.
In our belief, this technique should be reserved for high-risk patients in whom the risk of open surgery risk outweighs the benefit and medical treatment alone is not effective; patients who will not tolerate complex procedures; patients who would usually be recommended for endovascular interventions rather than open procedures; and critically ill patients who present to cardiac centers offering only basic services and cannot be transferred to a center with advanced aortic services, e.g., a hybrid room and proper cerebral monitoring systems, without a high risk of immediate mortality.

\section{Conclusion}

The early results of modified selective root reconstruction with aortic valve repair are excellent. This method provides a quick, reliable, easily reproducible, and technically undemanding valve-sparing technique for acute aortic root dissection.

\section{Abbreviations}

$C T$ : Computed tomography; ER: Emergency room; AR: Aortic regurgitation; PTFE: Polytetrafluoroethylene; CPB: Cardiopulmonary bypass; SVG: Saphenous vein graft; LAD: Left anterior descending artery; AVR: Aortic valve replacement; gH: Geometric height; eH: Effective height; STJ: Sinotubular junction

\section{Acknowledgements}

Not applicable

\section{Availability of data and material}

Data are available with the corresponding author upon request. All data were retrieved from the patient archives of the Cardiothoracic Academy of Ain Shams University. 


\section{Author's contributions}

The author has contributed to the content of the article. The author read and approved the final manuscript.

\section{Funding}

The manuscript is totally funded by the author without any external or undisclosed funding sources.

\section{Ethics approval and consent to participate}

The study protocol was revised and approved by the Ethical committee of Cardiothoracic surgery department at Ain Shams University and Faculty of Medicine Ain Shams Research Institute (MASRI) by which the patients' consent was waived due to retrospective nature of the study.

\section{Consent for publication}

No copyrighted material involved in this publication and subject to acceptance, author will sign an exclusive license to publish.

\section{Competing interests}

We all would like to concur that we have no conflict of interests or any undisclosed financial or commercial relations affecting this study.

Received: 11 February 2020 Accepted: 7 April 2020

Published online: 21 April 2020

\section{References}

1. Pape L, Awais M, Woznicki E (2016) Presentation, diagnosis, and outcomes of acute aortic dissection: seventeen-year trends from the international registry of acute aortic dissection. J Vasc Surg 63(2):552-553. https://doi.org/ 10.1016/j.jvs.2015.12.012

2. Chiu P, Miller DC (2016) Evolution of surgical therapy for Stanford acute type A aortic dissection. Ann Cardiothorac Surg 5(4):275-295. https://doi. org/10.21037/acs.2016.05.05

3. Urbanski PP, Hijazi H, Dinstak W, Diegeler A (2013) Valve-sparing aortic root repair in acute type A dissection: how many sinuses have to be repaired for curative surgery?t. Eur J Cardio Thorac Surg 44(3):439-444. https://doi.org/ 10.1093/ejcts/ezt042

4. Patterson BO, Cobb RJ, Karthikesalingam A, Holt PJ, Hinchliffe RJ, Loftus IM, Thompson MM (2014) A systematic review of aortic remodeling after endovascular repair of type B aortic dissection: methods and outcomes. Ann Thorac Surg 97(2):588-595. https://doi.org/10.1016/j.athoracsur.2013.07.128

5. Mookhoek A, Korteland NM, Arabkhani B, Centa ID, Lansac E, Bekkers JA et al (2016) Bentall procedure: a systematic review and meta-analysis. Ann Thorac Surg 101(5):1684-1689. https://doi.org/10.1016/j.athoracsur.2015.10.090

6. Aomi S, Nakajima M, Nonoyama M, Tomioka H, Bonkohara Y, Satou W et al (2002) Aortic root replacement using composite valve graft in patients with aortic valve disease and aneurysm of the ascending aorta: twenty years experience of late results. Artificial Organs 26(5):467-473. https://doi.org/10. 1046/j.1525-1594.2002.06957.x

7. Girardi LN (2008) Composite root replacement with a mechanical conduit. Oper Tech Thorac Cardiovasc Surg 13(3):148-160. https://doi.org/10.1053/j. optechstcvs.2008.06.004

8. Gaudino M, Franco AD, Weltert L, Benedetto U, Lau C, Gambardella I et al (2017) The role of neo-sinus reconstruction in aortic valve-sparing surgery. J Cardiac Surg 32(6):328-333. https://doi.org/10.1111/jocs.13143

9. Vojáček J, Žáček P, Dominik J (2017) Aortic valve repair and valve sparing procedures. Cor Et Vasa 59(1). https://doi.org/10.1016/j.crvasa.2017.01.025

10. Fagan, A., Pillai, R., Radleysmith, R., \& Yacoub, M. H. (1983, January). Results of new valve conserving operation for treatment of aneurysms or acute dissection of aortic root. In British Heart Journal (Vol. 49, No. 3, pp. 302-302). BRITISH MED ASSOC HOUSE, TAVISTOCK SQUARE, LONDON, ENGLAND WC1H 9JR: BRITISH MED JOURNAL PUBL GROUP

11. David TE, Feindel CM (1992) An aortic valve-sparing operation for patients with aortic incompetence and aneurysm of the ascending aorta. J Thoracic Cardiovasc Surg 103(4):617-622. https://doi.org/10.1016/s00225223(19)34942-6

12. Sarsam MA, Yacoub M (1993) Remodeling of the aortic valve anulus. J Thoracic Cardiovasc Surg 105(3):435-438. https://doi.org/10.1016/s00225223(19)34225-4

13. David TE, Feindel CM, Armstrong S, Maganti M (2007) Replacement of the ascending aorta with reduction of the diameter of the sinotubular junction to treat aortic insufficiency in patients with ascending aortic aneurysm. J Thoracic Cardiovasc Surg 133(2):414-418. https://doi.org/10.1016/j.jtcvs.2006. 09.049

14. Schäfers H-J, Schmied W, Marom G, Aicher D (2013) Cusp height in aortic valves. J Thoracic Cardiovasc Surg 146(2):269-274. https://doi.org/10.1016/j. jtcvs.2012.06.053

15. Kerchove LD, Boodhwani M, Glineur D, Poncelet A, Rubay J, Watremez C et al (2009) Cusp prolapse repair in trileaflet aortic valves: free margin plication and free margin resuspension techniques. Ann Thorac Surg 88(2): 455-461. https://doi.org/10.1016/j.athoracsur.2009.04.064

16. Subramanian S, Leontyev S, Borger MA, Trommer C, Misfeld M, Mohr FW (2012) Valve-sparing root reconstruction does not compromise survival in acute type A aortic dissection. Ann Thorac Surg 94(4):1230-1234. https://doi. org/10.1016/j.athoracsur.2012.04.094

\section{Publisher's Note}

Springer Nature remains neutral with regard to jurisdictional claims in published maps and institutional affiliations.

\section{Submit your manuscript to a SpringerOpen ${ }^{\circ}$ journal and benefit from:}

- Convenient online submission

- Rigorous peer review

- Open access: articles freely available online

- High visibility within the field

- Retaining the copyright to your article

Submit your next manuscript at $\boldsymbol{\nabla}$ springeropen.com 